Western University

Scholarship@Western

Education Publications

Education Faculty

6-2012

Examining the Mediation of Power in a Collaborative Community: Engaging in Informal Science as Authentic Practice

\author{
Anton Puvirajah \\ Western University, apuvirajah@gmail.com \\ Geeta Verma \\ University of Colorado
}

Horace Webb

Follow this and additional works at: https://ir.lib.uwo.ca/edupub

Part of the Science and Mathematics Education Commons

Citation of this paper:

Puvirajah, Anton; Verma, Geeta; and Webb, Horace, "Examining the Mediation of Power in a Collaborative Community: Engaging in Informal Science as Authentic Practice" (2012). Education Publications. 15.

https://ir.lib.uwo.ca/edupub/15 


\section{Examining the mediation of power in a collaborative community: Engaging in informal science as authentic practice}

Article in Cultural Studies of Science Education · June 2012

DOI: $10.1007 /$ s11422-012-9394-2

CITATIONS

10

3 authors, including:

\section{Anton Puvirajah}

The University of Western Ontario

16 PUBLICATIONS 71 CITATIONS

SEE PROFILE
READS

69

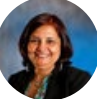

Geeta Verma

University of Colorado

19 PUBLICATIONS 38 CITATIONS

SEE PROFILE

Some of the authors of this publication are also working on these related projects: 


\title{
Examining the mediation of power in a collaborative community: engaging in informal science as authentic practice
}

\author{
Anton Puvirajah • Geeta Verma • Horace Webb
}

Received: 5 October 2010/Accepted: 5 January 2012/Published online: 26 January 2012

(C) Springer Science+Business Media B.V. 2012

\begin{abstract}
Focusing on the interplay of context and language, this study examined a group of high school students and their mentors' use of language during a robotics competition. This informal setting allowed us to gain insights into the mediation and manifestation of power within the group. Using critical discourse analysis of competition transcripts and interviews we found that both students and mentors felt a sense of ownership and community leading to symmetry in power amongst them. The shift in power led to greater student ownership and agency and created a space for authentic and meaningful science learning. The context of the robotics competition mediated discourse practices that were different from students' classroom experiences in that they were descriptive, relational, explanatory, and had an authentic evaluative dimension. This engaged the participants to co-construct and critique each other's knowledge claims thereby engaging in scientific practices that approximated the practices of scientists. Our study presents an argument that language and context reflexively influenced one another and reduced the imbalance of power amongst the participants thereby adding a new dimension to what has already been established about the conditions under which authentic science learning is likely to occur.
\end{abstract}

Keywords Informal science learning - Authentic science: language and context . High School Robotics · Mediation of power

\footnotetext{
A. Puvirajah $\cdot$ H. Webb

Science Education, College of Education, MSIT, Georgia State University, PO Box 3978, Atlanta, GA 30302-3978, USA

e-mail: apuvirajah@gsu.edu

H. Webb

e-mail: pwebb@ureach.com

G. Verma $(\bowtie)$

Science Education, School of Education and Human Development, University of Colorado Denver, Campus Box 106, PO Box 173364, Denver, CO 80317-3364, USA

e-mail: Geeta.verma@ucdenver.edu
} 


\section{Resumen Ejecutivo}

El propósito de esta investigación fue examinar la interacción entre contexto y lenguaje en un escenario de ciencia informal (Preparatoria Club de Robótica - High School Robotics Club) para obtener un conocimiento más profundo acerca de la mediación y la manifestación del poder entre estudiantes y mentores. El contexto de aprendizaje informal provee sitios alternativos para la producción de conocimiento en el sentido que la participación de los estudiantes es principalmente voluntaria, de opción libre, a su propio ritmo y no secuencial.

Argumentamos que el lenguaje de la ciencia, un producto de la comunidad científica, es extremadamente importante porque tiene un sistema único de recursos para crear significado y conocimiento científico. Además el lenguaje puede mostrar el grado con el que el poder es ejercido, usado, negociado, realizado, abusado, aceptado y desafiado. Por lo tanto, es importante examinar cómo se utiliza el lenguaje cuando se hace ciencia así como cuando se está aprendiendo y enseñando ciencia. Esta investigación nos permite crear experiencias para que los estudiantes participen y comprendan el lenguaje de la ciencia y para que puedan involucrarse con una participación más auténtica en la comunidad científica.

Nuestro estudio está enmarcado en la idea de que la naturaleza acumulativa del aprendizaje de la ciencia está fuertemente mediada socio culturalmente, y que las relaciones de poder existen en todos los contextos. Discutimos cómo el interjuego entre el contexto y las interacciones sociales facilitan relaciones de poder entre la gente. Posteriormente abordamos la sujetivización del estudiante y el rol del maestro y otros adultos en los contextos del aprendizaje de la ciencia. Adicionalmente, discutimos los factores que contribuyen al desarrollo de contexto(s) en los que los estudiantes pueden tener experiencias auténticas de aprendizaje de la ciencia y puedan participar disciplinadamente formando una identidad propia dentro del panorama científico. Conceptualizamos la noción de ciencia auténtica usando dos ideas: (1) participación productiva disciplinada (Engle \& Conant 2002); y (2) normas disciplinadas (Ford \& Forman 2006). Utilizando el Análisis Crítico del Discurso (CDA) y la Construcción de Tareas de Gee (2005a, b), examinamos el uso del lenguaje en un grupo de estudiantes de preparatoria y de sus mentores en el contexto de un concurso de robótica. El concurso de robótica ofreció oportunidades para examinar las interacciones estudiante-mentor y estudiante- estudiante, así como la manifestación de poder durante estas interacciones.

Los resultados indican que tanto los estudiantes como los mentores participaron en experiencias auténticas de ciencia a través de una participación productiva disciplinaria en la actividad de robótica. Los participantes tuvieron un fuerte sentido de comunidad, lo que facilitó el cambio hacía una simetría de poder y autoridad. Este cambio en el poder creó un espacio para un aprendizaje de la ciencia más auténtico y significativo donde el discurso de los estudiantes fue más descriptivo, relacional, explicatorio, y tuvo una dimensión más evaluativa (Gómez 2007). Además, apoyados en nuestros resultados, discutimos tres criterios que pueden ser usados para ofrecer a los estudiantes experiencias auténticas de aprendizaje. Consideramos que el tipo de conversación producida por los estudiantes y la comunidad construida en el concurso de robótica necesitan encontrar un camino en el salón de clases dado que la meta es que los estudiantes representen auténticamente las prácticas disciplinadas de la ciencia. Cuando los estudiantes logran esto, pueden construir el sentido de propiedad, comunidad, y de acción en sus propias experiencias de aprendizaje.

The role of language and the ways in which language is used to shape the dynamics of the educational process have long been of interest to researchers from diverse disciplines. 
Sociolinguists such as James Gee (2005a) propose that language is a cultural product and that it has no meaning outside of the community of its users. If this is the case, then the language of science, a cultural product of the scientific community, has no meaning outside this community. The language of science is profoundly important as it has a unique system of resources for creating meaning and more specifically, for creating scientific knowledge. As such it is important to examine how language is used in doing science and how this language is played out in learning and teaching science. This enables us to create specific and targeted experiences for students to participate, engage, and understand the language of science. Research on language in the science classroom reveals the importance of teachers' role in structuring students' experiences in talking and writing about science (e.g., Dawes 2004). Out-of-classroom science experiences (e.g., robotic clubs, science Olympiad, and science fairs) extend students' experiences into alternative spaces where there is greater potential for learning to be “...self-motivated, voluntary, and guided by the learner's needs and interests" (Dierking, Falk, Rennie, Anderson and Ellenbogen 2003 p. 109). John Falk (2001) argues that the intentional nature of participation outside of the formal classroom allows for self-paced learning that could also be non-sequential. In these less formal learning experiences, students have a voice and they are able to make choices about the types of science experiences in which they engage and the extent of their participation. This level of autonomy makes their experiences authentic, meaningful, and resemble scientific practice. Additionally, in these types of out-of-classroom experiences, the teacher's traditional role is diminished, and the changed role resembles more like that of the students. If teachers or other adults are present with the students during these out-of-school activities, their roles change to align with the free choice, non-sequential, self-paced, and voluntary nature of students' participation. Falk and Lynn Dierking (2010) argue that inclusion of free-choice science learning experiences allows for engaging and authentic educational delivery that encourages students to interact with their peers, adults, and their surroundings.

The use of language and discourse by the participants (teachers and students) are the means that is central to realizing the intended goals of learning. With the use of language in social settings, there is also invariably the manifestation of power. Language reveals, creates, reflects, obscures, and depoliticizes power ( $\mathrm{Ng}$ and Bradac 1993). Power is not a distant abstract, but a phenomenon that is played out in all types of everyday social interactions through the use of language. Michael Foucault (1979) argues that power is omnipresent in all human social endeavors. The context of these social interactions also becomes important in the way power is manifested through the use of language. Thus context influences the type of social interactions that could occur, and language is the primary instrument through which social interactions occur. Language used in a specific context can then show how power manifests in social interactions. That is, language can show the extent to which power is exerted, used, negotiated, realized, abused, accepted, and challenged.

Meaningful interpretation and analysis of language by members of a community or by researchers looking into to the workings of a community, whether it is discursive or otherwise, cannot occur independently of context. Since the term 'context' may have different meanings among different individuals and in different disciplines, before going any further, it is important for us to define what we mean by context as it relates to the work presented here. Our idea of context of language use stems from the notion that understanding or interpreting language relies on the manner, status, relationship, and assumed intent of the speaker and on the time and place of language use. The use of language, "cannot be properly understood, interpreted appropriately, or described in a relevant fashion, unless one looks beyond the event itself to other phenomena within which the event is embedded" (Duranti and Goodwin 1992 p. 3). This 'other phenomena' is the context that dynamically frames the 
language event and facilitates appropriate interpretation of the event. We agree with Alessandro Duranti and Charles Goodwin's (1992) notion that context should not be a set of static variables within which language transmission occurs, but should be considered mutually and dynamically reflexive with language. That is, language and context shape one another.

With this in mind then, focusing on the interplay of context, language, and power is an avenue to gain insights into broader aspects of social justice, equality and equity, and democracy within the science teaching and learning landscape. We add to this conversation by sharing our study on the interplay between context, language, and power during a high school robotics competition. More specifically, in this study we examined a group high school students and their mentors' use of language within the robotics competition setting to gain insights into the manifestation of power within the group. The robotics competition offered opportunities to examine student-mentor and student-student interactions as well as the manifestation of power during these interactions. We also simultaneously studied students' reflective narratives to understand the comparative aspects of their experiences in two pedagogical contexts: in class and in the robotics competition. This allowed us to elucidate how these two different pedagogical contexts influenced power relations between students and teachers/mentors. The study focused on the following research question: How does the language and context of the robotics competition reveal the mediation of power among students and their mentors?

\section{Theoretical underpinnings}

We frame our study within the idea that the cumulative nature of science learning is strongly socioculturally mediated and takes place in various learning contexts and that power relationships exist in all sociocultural setting (Dierking et al. 2003). Poststructuralists such as Foucault (1979) and Mikhail Bakhtin (1981) find the meaning of words in the words' relationship to one another without reference to non-linguistic forms. For these and other poststructuralists, the meaning of language is situated in the societal relationships to which it gives life. Thus, we begin this section with a discussion on how context and social interactions among people facilitate the manifestation of power, which can be observed through the use of language. We then extend this conversation to the subjectification of the student and the role of teachers and other adults in the science learning contexts. Lastly, we discuss factors contributing to the development of context/s that enable students to experience authentic science learning where they participate in productive disciplinary engagement by forming an identity of self within the scientific landscape.

Language, context, and the manifestation of power

Language reveals the manifestations of power, which are essentially human acts of control. These acts of control are "offers, requests, orders, prohibitions, and other verbal moves that solicit goods or attempt to effect changes in the activities of others" (Ervin-Tripp, O'Connor, and Rosenberg 1984 p. 116). Through these acts, power is used or exercised for social (person-centered) and utilitarian (task-centered) purposes. We argue that the context in which language is used and the opportunities and limitations the context offers, determines how and to what extent power is used for social and utilitarian purposes. That is, a particular context enables and defines social interactions between people, where acts of control, which can be conscious or subconscious, can become evident.

Exertion of power or acts of control can depend on context, but can also transcend context. It is also possible for social and utilitarian purposes to overlap during acts of 
control. That is, power exercised for social purposes could also have utilitarian purposes and vice versa. For example, a chemistry teacher exercises power primarily for utilitarian purposes by asking his students, "John and Susan, why don't we work on the stoichiometry section of the practice exam next?" The teacher's request can be thought of as an act of control to cause John and Susan to work on the stoichiometry section. However, the nature of the request also has a social purpose. We could infer that the nature of the language used (e.g., "Why don't we...") by the teacher reveals the type of social interaction/relationship that he wants to maintain with his students.

The teacher's request above was intended to garner compliance from his students. This form of language choice is an example of using effective power. Effective power is the ability to elicit compliance from the addressee (Ervin-Tripp, O'Connor, and Rosenberg 1984). In reference to the above example with the chemistry teacher, it is possible to examine the kind of power the teacher possesses and how his status played a role in the exertion of effective power relative to the students' status. Addressee compliance can be affected by the type of relationship that already exists and by the type of relationship that is desired. In addition, exercising effective power can occur through overt markings, justifying, and hinting (Ervin-Tripp, O'Connor, and Rosenberg 1984). We briefly discuss these below as we will revisit these three ways to exercise effective power in later sections.

Within the context of teacher-student interactions, there are certain perceived normative social rights and obligations of behavior that are expected. Exercising the social rights and obligations of behavior, like those of teachers and students for example, through the use of language will invariably be laden with control acts. The example presented above of the teacher asking the students to work on stoichiometry is an example overt marking of effective power. It is overt marking because the teacher overtly makes a request using language that he assumes will garner a certain desired outcome from the students.

Justifying and hinting are two additional ways of effectively exercising power. In justifying, the requester attempts to garner control by providing justification for an act. For example, a chemistry teacher requesting, "I would like you to make sure that you wash out your beakers well, if you don't you're going to get some weird results because of soap and other contaminants", is providing justification for asking the students to wash their beakers properly. We can think of the inclusion of justification as an attempt to provide greater credibility and increase the likelihood of compliance from the students. In the application of hints for effective power, the requester would provide hints to garner compliance or control. For example, when a teacher states, "If I were doing this I would pour the distilled water in before the ethanol" to a pair of students working on a laboratory exercise, she expects the students to do just that. The three examples of effective power presented above also illustrate both utilitarian and social purposes of power.

As we just described how effective power is used to garner control, it is also important to discuss factors affecting compliance or resistance to control acts. Foucault (1979) emphasizes that resistance defines power; especially the liberty to either resist or comply with acts of power. Thus power relations are defined by both acts of control (manifestation of power) and by the resulting acts of compliance or resistance. Simply hinting, politely asking, or providing justification does not always yield compliance. Most often, our acts of control are measured in a sense that we are relatively confident that we will get compliance. We, for example take into account the nature of the context and the relationship before acting to control.

When a request is made, the addressee gauges whether to comply based on the context of the request, the relationship to the requester, and nature of the request. For example, cooperative or joint activities in which individuals work toward a common goal, will 
garner greater compliance within the members of group than activities that compete for resources. The higher the "cost" for the addressee in complying with a request, the greater the likelihood he or she will resist or not comply.

High costs of compliance are incurred when (a) the control act interrupts the addressee, (b) compliance would undo the addressee's present or planned activity, (c) the proposed good is expensive or the activity is difficult, (d) the possessions in issue are owned by or used by the addressee, and (e) a subordinate is trying to control someone of authority beyond normal rights (Ervin-Tripp, O'Connor, and Rosenberg 1984 p. 120). High cost compliance (higher risk of non compliance) often involve the requester showing more politeness in the form of respect or esteem, flattery, or allusions to elicit solidarity between the addressee and the requester (Brown and Levinson 1978). However, this does not necessarily suggest a disingenuous effort by the requester to gain compliance. The requester may actually do this to work toward building solidarity between the requester and the addressee. When cooperation exists among a group of people, the cost of control acts within the group becomes lower.

Language used in control acts, whether they are for social and/or utilitarian purposes, has the potential to undermine the autonomy of the person to whom the language is directed (Brown and Levinson 1978). Foucault's notion of language is similar. Indeed, Foucault (1972) emphasizes that the use of language is an overt manifestation of discourse (which can be both discursive and non-discursive) that reflects and generates power, and may be liberating, oppressive, or a combination of both (Candela 1999).

Changing everyday praxis of teaching and learning through mitigation of power

John Dewey (1920) and Lev Vygotsky (1981) viewed human culture as the source of knowledge, and viewed language use and collaboration with more competent members of the culture as the most important aspects of knowledge construction. If this is the case, then the source of scientific knowledge also has its basis in the human culture. The practices of the scientific community are complex socially situated activities with their own particular linguistic traditions, values, rituals, and social structures that are weaved within the larger human culture. However, students in a largely adult-dominated culture of schools and school-like places are limited in the way they experience and gain knowledge, and more specifically they are limited in the way they come to understand and experience the practices of the scientific community (Duschl and Osborne 2002).

We contend that science learning is situated social activity that is heavily influenced by pedagogical context. As pedagogical approaches to science learning become authentic, the linguistic interactions, values, and social structures of student's science learning resemble the linguistic interactions, values, and social structures of practicing scientists (Roychoudhury and Roth 1996). When this occurs, students also come to understand the architecture of scientific knowledge (Ford and Wargo 2007).

The various discourses that students and teachers bring into the science classroom encompass situated or context-driven linguistic practices and accompanying values and social structures (Gee 2005a). It is also common to find among these discourses, differences and in congruencies in the linguistic practices, values, and social structures. These then exacerbate the imbalance of power among members of the science classroom and can be impediments to participation in scientific discourse and may not allow students to get opportunities to experience science in the making. As an example, in adult-dominated culture, students do not have the autonomy and thus are excluded from participating in certain authentic science learning practices. As such, students' definition of self within the 
scientific landscape does not include notions of being empowered by their understanding of science and scientific practice, and whatever science that is learned becomes distant, not their own, and less meaningful. The notion of students as subjects who need to be taught should be replaced with the notion of students who can give laws to themselves (Foucault 1979). The way Foucault envisions education goes beyond "freedom from" to embrace ideas of autonomy and self-power. This allows for students to acquire skills to exercise power and form an identity of self within the scientific landscape that approximates those of scientists. When all members of a group, such as a group of students, become empowered to shape and change how the group's goals are achieved, the members may realize that they are all in this together and experience a sense of community (Roth 2007). Wolff-Michael Roth suggests that the inherent need for people to be in some of form of harmony should lead to a sense of mutual responsibility and the pursuit of goals that are collectively constructed. Thus according to Roth, everyday praxis of teaching and learning should move toward building a community of stakeholders, especially among teachers and students.

Various researchers have studied student-student and student-teacher discourses in attempts to understand the contexts in which a true collaborative community is built among students and their teachers. Roth's (1993) study centered on a semester-long physics course that focused on student-selected and designed inquiry projects. Roth and Michael Bowen (1995) studied student-selected and designed projects for a unit on ecology. These studies reported that when teachers play support roles in these classrooms there was greater sense of community among students and their teachers.

Others have written of students and their teachers encountering data that neither students nor teachers can interpret, even though the teachers have backgrounds in the areas of science in which they are teaching (Kelly, Brown and Crawford 2000). In these cases, the teachers report that they become co-investigators with their students, resulting in greater symmetry in power and authority. It is noteworthy that this symmetry of authority is most evident in learning activities that take place outside the science classroom.

Daniel Edelson's (1998) three attributes of science learning activities are useful in thinking about contexts that produce symmetry in power and authority. Activities, (a) where students examine a problem with a high level of uncertainty in the solution, (b) that present meaningful consequence to students' lives, and (c) where the assessment of the student solution is as authentic as the problem itself, allow for the mitigation of power imbalances between the students and the teacher. When students act to construct their own knowledge and begin to see themselves in the role of scientists, the asymmetrical distribution of power initially favoring teachers shifts and at the same time collaboration and community building with their classmates, the teacher, and the scientific enterprise increases (Rosebery, Warren and Conant 1992).

Authentic science experiences address the imbalance of authority and power in the science classroom for students and teachers through building of a collaborative community of stakeholders. When this happens, the intents, goals, and responsibilities of the community have great potential to yield authentic experiences for the members of the community (Adams, Luitel, Afonso and Taylor 2008). We use Randi Engle and Faith Conant's (2002), and Michael Ford and Ellice Forman's (2006) work to frame authentic science learning. We argue that authentic science learning experiences affords students the opportunity to participate in meaningful linguistic interactions, since these learning experiences are situated in the activities and values of practicing scientists.

Authentic construction of scientific knowledge is a social practice that involves disciplinary critique. As such, students need not construct or reconstruct the scientific 
knowledge; rather they should have experiences in the practice of science, including its reasoning patterns, so that they come to understand the architecture of scientific knowledge (Ford and Wargo 2007). This understanding, we believe, is a precursor for students to move toward becoming more autonomous members in a de facto science learning community involved in productive disciplinary engagement. Engle and Conant's (2002 p. 400) use of the term productive disciplinary engagement also describes students' engagement in the practice of science. The authors differentiate between productive disciplinary engagement and disciplinary engagement. Disciplinary engagement within the learning context has to do with having "contact between what students are doing and the issues and practices of a discipline's discourse" (p. 402). Productive disciplinary engagement on the other hand is described as having disciplinary engagement be intellectually progressing. They propose four tenets of productive disciplinary engagement to describe authentic scientific practice within the learning context. These are: problematizing content, giving students authority, holding students accountable to others and to disciplinary norms, and providing relevant resources.

While these four tenets are broad attributes of productive engagement in many disciplines (e.g., art, theater, social studies) including science, Ford and Forman (2006) identify the following three disciplinary norms for authentic learning in science: social aspect of scientific practice, material aspect of scientific practice, scientific practice as an interplay between roles. The social aspect of scientific practice and learning encompasses public debates to explain natural phenomenon using stabilized norms and rules that are socially negotiable. The material aspect of scientific practice includes framing, measuring and representing the students' (researchers') account of nature in the public realm. The scientific practice as interplay of roles describes students as being both constructor and critquer of claims in order to ground the knowledge claims within the scientific enterprise, which contribute to disciplinary authority. It is important to note that student authority should not overshadow disciplinary authority but rather be exercised to understand disciplinary norms. We contend that Ford's three disciplinary norms for authentic science learning is facilitated by the presence of a sense of community, with shared goals and intents, among students and teachers.

We conclude this section by suggesting that when power is shared equitably among stakeholders in science teaching and learning, students and others (teachers and other adults) increasingly experience greater community among themselves and with the scientific enterprise. This enables students to participate in authentic science learning where they become both constructor and critique of scientific knowledge claims. As students continue to participate in authentic science learning, they also come to understand the 'architecture of scientific knowledge' and become comfortable in identifying and placing themselves within the scientific landscape.

\section{Using critical discourse analysis (CDA) to examine power relations}

Critical Discourse Analysis (CDA) can be used as a lens to provide holistic and rich descriptions of the way context and language shape lived experiences of individuals (Bogden and Biklen 2003). Using CDA, we analyzed language/text (e.g., written and spoken), discourse practices (e.g., how participants produced the written and spoken artifacts), discursive events of the robotic competition, as well as participants' reflections on classroom experiences. For the purpose of this study, we drew upon the following assumptions associated with CDA (Fairclough and Wodak 1997): (a) Power relations are 
discursive; (b) Discourse constitutes society and culture; Discourse is historical; (c) A sociocognitive approach is needed to understand how relations between texts and society are mediated; (d) Discourse analysis is interpretive and explanatory and uses a systematic methodology; and (e) CDA is a socially committed scientific paradigm.

Employing Gee's (2005a) ideas about situated learning, we examined the reflexive interaction of science learning context and language. When members of a language community speak, write, or use symbol systems (i.e., when they take part in discourse), they are taking part in constructing a certain reality about themselves and the world around them. Gee uses seven building tasks to show how language is used to construct human reality. That is, the purpose for using language is described by Gee's building tasks. Language is used to (1) create significance; (2) enact activities; (3) form relationships; (4) create, negotiate, and maintain identities; (5) affect the distribution of social goods (politics); (6) make connections among actions, words, or meanings to convey a message; and (7) privilege one type of knowing over another through the use of exclusive sign/systems and knowledge. For example, we may participate in a certain activity or activities in which people use a certain kind of sign/systems and knowledge to form certain kinds of relationships leading to shaping of individual and group identities. It is also important to understand that during a discourse event multiple buildings tasks could be emerging or taking place. In addition to showing how language is used to create reality, buildings tasks allow researchers to inquire about the use of language.

\section{Students and mentors as collaborators}

The study focused on the participants' linguistic interactions during the robotics competition. The participants included seven high schools students and two mentors. They were part of a larger robotics club comprised of fifteen students and five mentors. The mentors were a combination of teachers and engineering professionals. The students attended one of the two high schools located in a suburban metro city in the Southeastern United States. The teacher mentors taught in one of these high schools as well.

\section{Students}

Out of the seven student participants, two were female and five were male. Three student team members were from High School 1 (HS1), while the other four were from High School 2 (HS2). The two high schools are demographically very similar in that more than $90 \%$ of the student population was Caucasian. Students' participation in the robotics club was a voluntary after school activity. All students were included in the data collection during the three-day robotics competition and participated in semi-structured interviews within eight days of the competition. The seven students chose their own pseudonyms for this study: Shaggy Jones (SJ), Stretch Armstrong (SA), Nolan Strange (NS), Hope Wedgwood (HW), Faith Wedgwood (FW), Hans Fowler (HF), and Philemene Aaron (PA).

\section{Mentors}

A male teacher mentor and a male engineering mentor participated in the study. The teacher mentor had 32 years of teaching experience, including 2 years at HS1, and holds national certification and a Master's Degree in Science Education. He has been involved in robotics for 7 years. The engineering mentor was not a certified teacher, but is a licensed 
mechanical engineer with a Master's Degree in Engineering. Both the mentors took part in all aspects of the study including participating in semi-structured interviews. The mentors were also given pseudonyms; Scott Bruce (teacher mentor) and George Mitchell (engineer mentor). The teacher and the engineering mentor were purposefully chosen to explore their experiences with the robotic activities and classroom or industry contexts.

\section{Robotics competitions as a context for enacting authentic science}

The context of the study was a regional high school robotics competition, where teams of students entered their robots to compete against one another. Students designed and constructed the robot that they entered in the competition during a 6-week build period immediately before the competition. The students were asked to design a robot that could be navigated and maneuvered to collect balls and place these balls in trailers attached to opposing teams' robots. The robotics competition aimed to develop high school students' interests in science and technology careers. Our study focused on a robotics team's discourse as they participated in the competition.

The students placed themselves in one of four units within the robotics club; one unit produced the mechanical design, another produced the computer interface for the robot, another handled the graphic design for the team's promotion and public relations, and the remaining unit handled logistics and coordinated the activities of the various units. Students were free to move among these units. Three certified science teachers and two practicing engineers acted as mentors to support the students in their tasks; however, the students were in charge of every aspect of the project within the constraints of budget and the team's expertise. The robotics club applied for and received a National Aeronautics and Space Administration (NASA) grant of $\$ 8,000$ and an award of $\$ 1500$ from Women in Technology (non-profit funding agency to support women participation in science and technology) to support their activities. The competition organizers supplied the club with the robotics kit containing a variety of components including various computer interfaces, digital and analog sensors, and various structural and drive train elements.

\section{Competition setting}

The regional robotics competition was held at a metro area convention center in the Southeastern part of the United States. A pit area, where the team members worked on assembling and making minor modifications to the robot was available for all the 42 teams in the regional competition. The remainder of the operational area included judges' area with tables and public address system, scales for certifying robot weights, and "the cage" (a rectangular enclosure used to certify the dimensions for the robots). This space also included a practice area, a large electronic signboard for announcements, and a help desk where diagnostic equipment was available for testing electronic components. The students had opportunity to assume various roles and responsibilities during the competition; these were robot driver and coach (co-driver), safety captain, pit crewmember, and scout.

One of the most important functions that team members fulfilled during competition was that of pit crewmember. The pit crew consisted of the engineering mentor, the driver, and coach. At times, other members of the team worked in the pit for short periods of time when heavy lifting was required, but the small area of the pit and the size of the robot made it impractical for more than two or three people to work in the pit at any one time. The pit 
crew repaired the robot between rounds of competition. These repairs included structural modifications, repairing mechanical, electrical, and software failures.

The robotics team also conducted various scouting activities during the competition. There were six full time scouts. However, during the competition, anyone with a free moment became a scout. During practice and competitive rounds, scouts were responsible for observing and rating other teams' robots. The organization that hosted the robotics competition produced a rating sheet on which scouts recorded their impressions of the other teams' robots. Between rounds, scouts were responsible for going to other teams' the pit areas to gather intelligence concerning the other teams' robots and to promote the virtues of their robot.

\section{Documenting interplay of language and context}

The data collection for the study took place in two stages; (1) during the regional competition, and (2) during semi-structured interviews in the eight-day period after the competition. The context of the robotics club allowed us to work with a purposeful and convenience sample. The sampling was purposeful because it allowed us to work with information and data rich context and participants to carry out in-depth examination of issues associated with our research purpose. Convenience sampling method was used since the robotics team met after school hours at one of two local high schools, where one of the researchers is a science teacher. As this was a qualitative study, participants' use of language and written materials or graphic products in the context of the robotics club became data sources.

Video and audio recordings of language

Records of language were one of the principal sources of data for this study. A small handheld digital video recorder was used to record the spoken language and movements of students and their mentors as they did various robotics activities. The video recordings also provided a record of instances that might be the subject of field notes, such as the location of students in the workspace, students and the mentors' gestures and facial expressions, and how students employed and manipulated equipment that were part of their activities.

Researcher's reflective journal

During the course of the study, we kept notes that included reflections on what transpired in the course of the robotics team's activities and in the process of coding the transcripts for participants' use of language. The journal is a record of the process through which we developed linguistic constructs such as the discourses that were enacted by the participants during and in response to their learning experiences.

\section{Student and teacher/engineer interviews}

The seven students were interviewed once during the course of the study. The students were interviewed by the researchers to learn about and understand their experiences in participating in the robotics club and in learning science in their classroom. The mentors (teacher and the engineer) were also interviewed. The questions and prompts for the 
mentors focused on their impressions of science learning/teaching in the robotics team and the science classroom and teacher mentor's and students' relationships in the robotic clubs and the science classroom.

\section{Examining the interplay of language and context}

To examine the interplay of language and context, the paragraphs of the video and interview transcripts were reduced to sentences, and these sentences were broken into clauses that dealt with a unitary topic or perspective. The clauses were then marked for tone units and pause, and analyzed for the significance of stress. Further, to analyze participant interviews, we read the initial transcripts while listening to the original recordings and determined whether there were any larger natural structures such as stanzas in the interview answers. Both types of transcripts were subjected to formfunction and language-context analysis (Gee 2005b) to identify the discursive resources such as concepts, phrases, and expression used by the participants. Form-function analyses examine language with a focus on grammatical form to study social context of language usage, while language-context analyses examine how context influences use of language and vice versa. The participants' discursive resources that were identified during these analyses were then coded using Gee's (2005a) Building Tasks that formed the a priori categories for codes. The Building Tasks that were most evident in the study data were activities, identities, relationships, politics (in the sense of distribution of social goods), and sign systems and knowledge. The Building Tasks served as a starting point for constructing the secondary codes that emerged from the regularities that we interpreted in the data. As we reviewed the transcripts, we developed understandings about the ways the participants were using language to accomplish the Building Tasks during the robotics activities and while being interviewed. The discourse analysis therefore created categories that "do not belong to individuals but to the culture and are merely realized in a concrete manner by the individuals" (Hsu, Roth, Marshall, and Guenette 2009 p. 1119). Table 1 shares an example of the use of Gee's Building Tasks as a priori codes and the use of secondary coding. This approach allowed us to construct a coherent picture of participants' interaction within the robotics club to examine student-mentor interactions and power relationships.

\section{Human as instrument}

One of the chief criticisms of CDA (Wood and Kroger 2000) is the bias that the researcher brings to the project. We recognize the inherent subjective nature of our analysis and interpretations within this study. CDA is a linguistic activity that is no less dependent on the context (including the researchers) in which it is conducted than any other linguistic act. This is to say that a particular discourse analysis is situated in a particular time and place, and that a particular analysis may be meaningful in certain ways and not others. However, we provide a "thick description" (coding transcripts, development of ideas and explanations about the situated use of language, and peer debriefing etc.) that was drawn from our interpretations of the language used by the study's participants (Geertz 1973). This description makes it possible to draw parallels with similar situations and might allow predictions to be made about what might happen in these similar situations. 
Table 1

\begin{tabular}{|c|c|c|c|c|c|}
\hline Speaker & Utterance & $\begin{array}{l}\text { Building } \\
\text { Task }\end{array}$ & $\begin{array}{l}\text { Secondary } \\
\text { code }\end{array}$ & $\begin{array}{l}\text { Discursive } \\
\text { resource }\end{array}$ & Context \\
\hline PP & $\begin{array}{l}\text { If we take off the universals, } \\
\text { and put on the gummies that } \\
\text { will help traction because } \\
\text { we'll go from passive front to } \\
\text { a four-wheel drive, but it will } \\
\text { change the handling, and } \\
\text { make us even lighter in the } \\
\text { front. We're screwed for } \\
\text { center of mass }\end{array}$ & Relationships & $\begin{array}{l}\text { Ownership } \\
\text { and } \\
\text { solidarity }\end{array}$ & $\begin{array}{c}\text { First person } \\
\text { plural } \\
\text { pronouns }\end{array}$ & Competition \\
\hline PP & $\begin{array}{l}\text { If we take off the universals, } \\
\text { and put on the gummies that } \\
\text { will help traction because } \\
\text { we'll go from passive front to } \\
\text { a four-wheel drive, but it will } \\
\text { change the handling, and } \\
\text { make us even lighter in the } \\
\text { front. We're screwed for } \\
\text { center of mass }\end{array}$ & $\begin{array}{l}\text { Knowledge } \\
\text { and activity }\end{array}$ & $\begin{array}{l}\text { Scientific } \\
\text { language } \\
\text { and } \\
\text { enactment } \\
\text { of science }\end{array}$ & $\begin{array}{l}\text { Dialogic } \\
\text { argument }\end{array}$ & Competition \\
\hline PP & $\begin{array}{l}\text { If we take off the universals, } \\
\text { and put on the gummies that } \\
\text { will help traction because } \\
\text { we'll go from passive front to } \\
\text { a four-wheel drive, but it will } \\
\text { change the handling, and } \\
\text { make us even lighter in the } \\
\text { front. We're screwed for } \\
\text { center of mass }\end{array}$ & $\begin{array}{l}\text { Knowledge } \\
\text { and activity }\end{array}$ & $\begin{array}{l}\text { Scientific } \\
\text { language } \\
\text { and } \\
\text { enactment } \\
\text { of science }\end{array}$ & $\begin{array}{l}\text { Scientifically } \\
\text { situated } \\
\text { language } \\
\text { (meaning } \\
\text { potentials) }\end{array}$ & Competition \\
\hline
\end{tabular}

\section{Shifting roles of students and mentors in an informal setting}

We present in three sections our findings on how language and the context of its use in the robotics competition reveal the mediation of power among students and their mentors. In the first section, we intentionally present a short segment of a transcript from a conversation among three members of the robotics team to highlight the salient aspects for our findings in detail. For brevity's sake, subsequent discussions of the findings using other, longer transcripts illustrate certain general similarities in language and context among the conversations, and thus yield interpretations similar to our interpretations of the first transcript.

Scouting activity: examining the symmetry of power among the scouting team members

As part of preparing for the robotics competition, each team was encouraged to "scout out" their opponents to help make decisions on strategy and design modification to gain any advantage in the competition. Our discussion focuses on what is revealed about the mediation and manifestation of power within the scouting context as the students communicate with each other. 
Transcript 1 presents a discussion among four members of the robotics team, who had volunteered to serve as scouts, as they met after observing early practice rounds of the robots competing with each other. Each scout was assigned to observe the performance of several robots. In addition, they were to visit the pit areas of the teams responsible for the robots, interview the team members, and undertake close-up inspection of the robots' construction to get a better sense of the durability and capabilities that might not be obvious from observing them at a distance during the practice rounds. The transcript below shows the four scouts sharing their observations and opinions of the competing teams and the robots.

\section{Transcript 1}

\section{Speaker Utterance}

NS-1 1102, the, green one, has really good way of knocking the balls off the, uh, rack. Yeah but it's not so good for that. Uh, good speed too, but like I said not so good for hurdling.

SA-1 The same thing it uses to pick 'em up?

NS-2 Yeah but it's not so good for that. Uh, good speed too, but like I said not so good for hurdling.

HF-1 Wait! Dude! I saw it on the test field and it hurdled great.

NS-3 It stunk in the practice round. Maybe there's, uh, like, a problem?

SJ-1 OK. After go back and talk to the crew and see if maybe they, uh, didn't try hurdling in that round or what, OK?

NS-4 Yeah, movin' on. Alright. Uh, the driver's not bad, but the 'bot was broken at the end of the round. There was a lot of bangin'. I asked about the repairs and the crew chief said it was no problem. Good herder and a definite rabbit. I'd say it's pretty strong overall.

SJ-2 Does it do hybrid?

NS-5 Uh, Yeah it went flyin' down and slammed the wall. So, it got two lines but it probably didn't help the mechanics much.

In the above transcript, we can tease out the manifestation of power among the three participants within the context of the conversation and the relationships that they have with one another. The first example of this is when HF-1 says, "Wait! Dude! I saw it on the test field and it hurdled great," interrupting and then countering NS-2's initial statement about the robot not hurdling well ("...but like I said not so good for hurdling”). HF saying, "Wait! Dude!" is an example of effective use of power through overt marking to get compliance. HF uses this power to interject and present his view of the robot to his teammates. The overlapping of utilitarian and social purpose of power is also seen here. The utilitarian nature is that HF wants to get his point across so that the group can also consider it. The social purpose is manifested through his choice of words used to interject and address his classmate. "Wait!" and "Dude!" are not formal utterances and thus their use highlights the informal nature of the relationship among the four scouts. Our interpretation of these utterances can also be extended to show that the scouts are accustomed and comfortable with each other.

Another example of effective use of power is seen when SJ-1 states, "OK. After, go back and talk to the crew and see if maybe they, uh, didn't try hurdling in that round or what, OK?" Here, SJ uses effective power through hinting to move the conversation along to other aspects of the scouting results (i.e., SJ-2 "Does it do hybrid?"). He does this by simply saying "OK". The utterance "OK" is used as a hint to stop the current direction of 
the conversation and move on (utilitarian use of power). Subsequently, NS-4 with his response, "Yeah, movin' on..." acknowledges the hint to move on and complies. Next, SJ1 continues to use effective power through overt marking to get the group to go to the opposing team and ask whether they "hurdled in that round" (utilitarian use of power). Similar to our previous interpretation, the social purpose of power can be discerned from SJ's use of language and from our understanding of the context within which the language is used. SJ's relationship with his teammates is such that he does not struggle to find appropriate words to redirect the conversation or to request that his team speak to the opposing crew about the hurdling.

We now turn our discussion to the nature of power manifested in the above transcript. We presented examples of effective power and highlighted the utilitarian and social purposes of effective power. What becomes obvious in the above transcript is that power relationships among the four scouts were neither disproportional nor asymmetrical. Although power distribution may not have been absolutely equal, any asymmetry in power that existed was minimal. We can also see that there was no resistance to either HF's or SJ's control acts. In addition, for HF and SJ, the cost of getting compliance was relatively low because of the relationship among the members of the group. Thus, we suggest that the higher the cost of compliance, the greater the likelihood of getting non-compliance and vice versa. We see in the above transcript that the three scouts work cooperatively toward a common goal of getting as much information as possible about the opposing teams' robots. That is, they share common responsibilities, interests, and goals with respect to their participation in the activities of the robotics club. The cost of control acts among individuals who share common goals, as in the case of the three scouts, is generally lower than for individuals who do not share common goals.

When there is symmetry in power distribution among individuals there is also a greater likelihood of shared interests among them. Edelson's (1998) three attributes for science learning that produce symmetry in power and authority can also be seen in the above conversation.

First, high level of uncertainty in the solution to the problem-The problem the scouts faced was that they needed to get as much information as possible about their opponents' robots to help their own team strategize appropriately for the robotics competition. There is no predefined or a correct set solution for this. The solution is uncertain since the problem is based on real circumstances and situations of the robotics competition. We were further able to gain a glimpse of the uncertain nature of the solution from the short conversation among the scouts. Both NS-2 ("...but like I said not so good for hurdling...") and HF-1 ("...I saw it on the test field and it hurdled great...") have differing views of the hurdling performance of the robot that they observed.

Second, activities have meaningful consequences-Indeed the activity that the scouts participated in is meaningful for several reasons. One reason it is meaningful is that their scouting report will be used to strategize for their own competition, thus having consequences in the way their own robot and their team perform in the competition.

Finally, assessment is as authentic as the problem-One of the ways the solution to the problem is assessed within the context of the robotics competition is tied to the meaningful nature of their activities. The degree to which the scouting information is used in strategizing for participating in the competition and the general performance of the robot in the competition are forms of authentic assessment of the solution.

We presented earlier Engle and Conant's (2002) notions of disciplinary engagement and productive disciplinary engagement. We contend that the scouts' conversation presented above approaches productive disciplinary engagement; that is, productive "science" 
engagement. Using Engle and Conant's (2002) four tenets of productive disciplinary engagement, we show below how this is the case:

(1) Problematizing content-The scouts are involved in finding appropriate solutions for their authentic problem of getting information on opponents' robots. Thus, the three scouts experience problematized content in scientific enterprise through their activities in the robotics competition;

(2) Giving students authority-The students in the robotic club including the scouts have much autonomy and power, thus have authority to navigate through their problematized content on their own with symmetrical sharing of power among all members of the team. They are neither coerced to nor limited from participating in the robotics activities;

(3) Holding students accountable to others and to disciplinary norms-The four scouts are held accountable to each other since their interests within robotics context are shared. As a collaborative activity, where power is shared symmetrically among the students, they are empowered to hold each other accountable for their responsibilities. The students in the robotics competition, including the scouts, are also held accountable to disciplinary norms by each other and by the prevalent culture of the robotics competition. That is, students have certain emerging and developing ideas about the norms of scientific enterprise, and they hold their peers accountable for adhering to these norms. An example of this is when SJ-1 states, "... go back and talk to the other crew and see if maybe they, uh, didn't try hurdling in that round...". After hearing contradictory information about the hurdling ability of one of their opponent's robots from NS and HF, SJ wanted to reexamine this by speaking with the opponents. Instead of just taking the contradictory information and making the best out it, the team, in line with disciplinary norms within the scientific enterprise, went on to collect more data on the hurdling ability of the robot; and

(4) Providing relevant resources-The three scouts have the necessary resources to carry out their scouting and other competition related activities. An outside entity or an agent does not necessarily have to provide the resources to the scouts. Because of the nature of the collaborative community that exists with the robotics team (including the scouts), the team is empowered to determine what resources they need and obtain these resources using their own initiative. A team that shares interests, goals, and responsibilities, and is empowered is less likely to stand idly by and wait for an outside entity to provide them with relevant resources.

Ford and Forman (2006) elaborate on disciplinary engagement in science by providing three disciplinary norms that are characteristics of authentic learning in science and approximate the scientific enterprise. We contend that these characteristics are present in the activities of the robotics team, including the scouting activity:

(1) Social aspect of scientific practice-The evaluation, modification, and creation of scientific knowledge is a social venture involving the larger scientific and other stakeholder communities. Similarly, the activities and the outcomes of the robotics team are realized through social negotiation of knowledge claims by individuals within a collaborative community who share common signs and language;

(2) Material aspect of scientific practice-scientific practice involves assessing the validity and the correspondence of the claim with how the natural world functions. That is, scientific claims should align with the material events occurring in the natural world. The activities of the robotics team align with the material aspect of scientific 
practice. As suggested earlier when we discussed holding students accountable to disciplinary norms, the alignment is present because students collect, frame, and represent data based on disciplinary norms expected during participation in scientific enterprise. SJ-1 stating that they should reexamine the hurdling issue by speaking with the opposing crew is an example of the material aspect of scientific practice being present in the robotics activities. The scouting team was not satisfied with the initial conflicting and inconsistent results on the performance of the opposing robot. The team initially tried to rationalize the difference through discourse. However, another scout (SJ) stopped the conversation (SJ-1- "OK.") and suggested that they speak to the opposing crew. We interpret that the conflicting reports of the same robot's hurdling capabilities was not in conformity with the way nature behaves, and thus the reason for $\mathrm{SJ}$ to initiate the reexamining process; and

(3) Scientific practice as interplay of roles-The practice of science involves individuals playing the roles of both a constructor and critiquer of knowledge claims. Much like what happens in the scientific enterprise, the scouts constructed and critiqued knowledge claims. NS-1 proposed certain knowledge claims about their opponent's robot including, "...the, green, one, has really good way of knocking the balls off the, uh, rack...Uh, good speed too, but like I said not so good for hurdling." NS made the claim that the green robot is good for knocking balls off the rack and for speed, but not so good for hurdling. HF-1 acted as a critiquer for the claim about the robots hurdling capabilities, illustrated in his statement, "Wait! Dude! I saw it on the test field and it hurdled great."

So far, we shared a conversation from the scouting activity to highlight the presence of effective power in both utilitarian and social forms and that the context and the relationship enabled near symmetrical manifestation of power and authority. We also showed how symmetry in power and authority leads to the presence of a collaborative community, which has the potential to provide individuals with authentic experiences. Additionally we discussed how the scouts were engaged in productive science engagement and in authentic science learning.

Symmetry in power leads to authentic experiences

The interview data explicates the differing roles the students assumed in the robotics competition and in their science classrooms. Students' use of "we" and "us" in the interview data is prevalent as they reflect on their participation in the robotics competition. Equally compelling is the complete absence of these expressions during interviews when students speak of their experiences in the science classrooms. In the following statement, SJ shared that robotics was different from his physics class labs:

In robotics it takes us six weeks to do one project because it is so huge. We have ta' [sic] plan everything out, safety is a huge deal. So, I mean, we have ta' [sic] do everything by the books and you don't have time to do these things in physics. You can't just take six weeks out of the curriculum and do a project 'cuz you won't get what you need done and so you have to do the couple-of-day labs, one two three maybe a week, at most, but never a six weeks project and that is why robotics isn't part of the curriculum, at the moment.

During the interviews, all the students mentioned aspects of the robotics competition as being real, accessible, and intense, and having common goals. In contrast, they referred to 
their experiences in their science classes as contrived, vague, and lacking intensity. Students found their participation in the robotics competition as real and accessible. These is because they participated in meaningful disciplinary engagement (Ford and Forman 2006) and they were subsequently held accountable for disciplinary norms (Engle and Conant 2002) in the context of scouting activity and in conversations in the pit area concerning the robot's traction. Because both the robotics competition and the classroom are social settings, these discursive distinctions spilled over into the language used by students to describe relationships in these two contexts. Another example of this distinction is illustrated when SJ states, "you might like all the concepts; the physics about it, but you never got a chance to get hands-on with the mechanics or electrical. You can do all the book-smarts and everything about it." In the course of the passage, SJ draws a distinction between disciplinary knowledge that includes "the concepts," the "physics," and "the book-smarts," and practical application of knowledge "to get hands-on". SJ further explains:

I didn't have too much to do with electrical or programming, but my knowledge has grown on especially how to use the things I learn in school; I actually put them somewhere. I actually use that math. The Pythagorean Theorem or Ohm's Law, we call it Pythagorizing actually moving that into something, we use it, whoever needs to know what the hypotenuse of a triangle is until you think about the robot can only be this tall and that's the best way to find its starting position because the hypotenuse is the longest part, so we actually have a place to use those applications.

We recognize that the extended period over which the project occurred lent itself to the students' participation in meaningful disciplinary engagement in the robotics club activities. As an example, the 6-week robot build time before the actual competition is an extended period of time compared to the time that students normally get in the classroom to engage in science. The extended time is necessary because building a functioning robot is intricate and involved. For students who were involved in the 6-weeks of robot building process, the engagement was meaningful, and provided them with a space "to get handson" and create new knowledge.

\section{Scouting sheet: deconstructing the [im]balance of power within a collaborative community}

In the following discussion we will use transcript 2 to illustrate how the robotics team's almost symmetrical sharing of power and authority leads them to have authentic science experiences. In our discussion we trace the conversation using mediation and manifestation of power as a lens to examine the nature of the robotics team's scientific engagement. Transcript 2 is the continuation of the scouting conversation presented earlier. During their conversation, the students discover that a very important piece of data was missing from the scouting sheet they were using. In response to this discovery, the students discuss what to do about the scouting sheet. The students then decide that they would calculate a ratio of points scored to points penalized and agree that one of the team members would collect the pertinent data, do the calculations, and keep the records.

\section{Transcript 2}

\section{Speaker Utterance}

SA-1 Yeah, right dude! 1957's hybrid's got a flipper made from plastic from a pool toy that knocks a ball down and they get two lines too. So, they get 20 points 
there. It's got good speed and maneuvers well. Good driver. It knocks down balls really strong. Good speed too. It doesn't hurdle well. I didn't see it, but it might place balls too. It scored points but the refs'll penalize it a lot for knocking other robots in their zone.

HF-2 It's (robot \#?) a lot like ours but it doesn't have good control. The lifting rack is two stage not three. The arms can scoop or grab but the ball slips out most of the time. It uses a bungee cord around the arms to capture the ball, slow and it won't hurdle. They might be able to place balls but I doubt it. I think the speed is about the same as ours but the driver's not so good. They'll lose a bunch of points in penalties too.

PA-1 I saw it in mine too.

SJ-3 Anybody else see that?

FW-1 Lost points for penalties?

SJ-4 Yeah.

[General, unintelligible conversation].

SJ-5 Ok. Um, if that's a problem, we need to scout it. We need to show that in our reports. How do we do it?

HF-3 We could calculate a ratio of points scored to points penalized, or something.

SA-2 Ooow? How about net points? It's...

PA-2 Um, No!.

SA-3 …easier.

PA-3 Um, uh, Net points might tell us what we need. What if we can't scout all the matches? Um, If we calculate net points, then, like, for the teams that we scout a lot it might look like, um, they're better than they really are and for the ones that we don't they might look like they're not so good. Well, um, the ratio won't change as long as they don't change something about what they're doing like a better driver or something

[General, unintelligible conversation].

SJ-6 Why? Um, well....

HF-4 They assign the alliances. Like, we don't get to choose who we play with and against.

SJ-7 ... well, we can talk to the other teams, um, and ask the driver to take it easy and not to bump in the zone and stuff. And we do choose if we get to the finals, so we can definitely use it. Alright, hold it! Shut up! Um, what do you want to do? We don't have much time before the next rounds, we've gotta move. Let me see the hands of everyone that wants a measure of points scored and points penalized. OK. So, good. Which kind of measure? Raise your hand if you want the ratio. OK, it's unanimous. I'll tell Zippy to get the numbers and to put in on his spreadsheet. Um, OK, let's go back and scout the next two rounds and meet at 3:00. Stop! Hold it! Let me have all the scouting sheets.

The conversation continues with the scouts reporting on their scouting activities (SA-1, HF-2, PA-1). They report on the various functionalities of the robots that they observed. For example SA-1 reports that the robot he observed "...got a flipper made from plastic from a pool toy..." and that it has good speed and hurdles well. The scouts also report that while the robots gained points for various functionalities and maneuvers in the practice competition, they also lost points and were penalized for illegal maneuvers. Our first instance of effective power is seen when SJ-3 says, "Anybody else see that?" asking the team if others had also seen their robots lose points in penalties. This is an example of the 
Table 2

Examples effective use of power from transcript

SJ-3: Anybody else see that?

SJ-5: If that's a problem, we need to scout it

SJ-5: We need to show that in our reports

SJ-5: How do we do it?

SA-2: How about net points?

PA-2: No

PA-3: What if we can't scout all the matches?

SJ-6: Well, we can talk to the other teams, um, ask the driver to take it easy and not to bump in the zone and stuff

SJ-6: Alright, hold it Shut up!

SJ-6: What do you want to do? We don't have much time before the next rounds. We've gotta move

SJ-6: Let me see hands of everyone that wants a measure of points scored and points penalized?

SJ-6: Which kind of measure? Raise your hand if you want the ratio

SJ-6: I'll tell Zippy to get the numbers and to put in on his spreadsheet

SJ-6: Ok, let's go back and scout the next two rounds and meet at 3:00

SJ-6: Stop! Hold it! Let me have all the scouting sheets
Type of effective power

Overt marking

Justifying

Overt marking

Overt marking

Overt marking

Overt marking

Justifying

Overt marking

Overt marking

Justifying

Overt markings

Overt markings

Overt marking

Overt marking

Overt marking

use of effective power for utilitarian purposes because SJ uses the context of the robotics competition and his relationship with his teammates to make this request. Again, we see the effective use of power as SJ-5 tells his teammates that if points lost is an issue, then they'll need to show that in the scouting report ("SJ-5 "..if that's a problem, we need to scout it. We need to show that in our reports..."). He then asks his team for suggestions on how to do this (SJ-5 “...How do we do it?”). Table 2 presents instances of effective power usage in the conversation.

On first inspection, it may seem as if the simple question posed by SJ-3 ("Anybody else see that?") is not significant to our analysis. However, SJ's question highlights the very nature of power and its potential role in enabling scientific engagement. With this question, SJ demarcated himself from the rest of the scouting team by assuming the role of facilitator and coordinator within the team. He did this by first asking the question, and then by coordinating the remaining conversation. We see in the above conversation and in Table 2 that SJ has the most usage of effective power; specifically, he uses effective power to coordinate the conversation and the activities of the scouting team.

SJ's use of effective power garnered compliance from his peers at relatively low cost to him. That is, SJ likely did not worry about how he needed to address his teammates or about the appropriate choice of words in coordinating the conversation and activities of the team. SJ-7 commanding, "All right, hold it! Shut up!" is an example of effective power used with his teammates at a low cost. It is low cost because of the context of the team's activities and the nature of the relationship existing among the team members. As mentioned earlier, high cost often involves the requester being more polite to the addressee, and the language used by SJ is not necessarily polite. If the context and/or the relationship change, the cost of getting compliance will also change. Thus, it may be unlikely that SJ would use the same utterances with individuals he just met at the competition. There is low cost for SJ's control acts since the individuals on the team, including SJ are working 
toward a common goal. There is accord among the team members; because of this, the members accept to comply with SJ's control acts.

SJ emerges as an authority figure within the collaborative community. SJ's effective power utterances outnumber those of his peers as he uses these utterances to direct some of the activities of the scouting team. This suggests a somewhat asymmetrical distribution of power; however, we contend that the distribution of power and authority continues to be symmetrical among the team members because there is a sense of community within the team. Our conjecture is based on the idea that individuals within a community share goals, responsibilities, and interests and that the scouting team members, including SJ, are members of a collaborative community. There is not necessarily a disproportional amount of "unchecked" power and authority wielded by SJ. In fact, SJ's overt power is matched or checked by his teammates' choice and willingness to comply with his acts of control. In essence, the team provides SJ with his power, and the team can also take away the power. We also see in the transcript that SJ did not abuse his power, but used it to coordinate the activities of the scouting team to realize the team's shared goals. He did this by facilitating open conversations among the members of the team, asking for clarification, providing direction to the activities, getting members of the team to provide suggestions for overcoming issues, and getting the whole team involved in the decision making process. In sum, when individuals have meaningful experiences within a collaborative community, the power relationships found among them works to continue to develop these experiences.

We identify Edelson's (1998) three attributes of science engagement for producing symmetry in power and authority in the team's conversation about the scouting report. Using these three attributes we found that: (1) the scouts were involved in activities where they examined a problem with a high level of uncertainty in the solution. We notice this as students take turns trying to make sense of their scouting reports, and then offer suggestions for modifying the scouting report; (2) the scouts' activities had meaningful consequences to students' lives. There are several of these, including the one mentioned earlier in the analysis of the first transcript. Another one is that, since the students participated in activities of the robotics team voluntarily, there are personal (meaningful) reasons for their participation. If it was not meaningful in some way, students may not have participated; and (3) the assessment of the scouts' activities was authentic. The activities the team members participated in, and the knowledge and the artifacts they created were assessed in different ways by different people. For example, there was assessment by the team members, competing teams, the public visiting the competition, and the competition judges.

We now shift our discussion from describing the symmetry of power among the scouts to briefly discuss how the team conversation shows evidence of productive disciplinary engagement (in science) and the presence of disciplinary norms characteristic of the scientific enterprise. The scouts' conversation continues to show evidence of productive disciplinary engagement as they problematize their scouting activity, have authority to determine the nature of their engagement within the activity and the nature of direction the activity should take, and hold themselves accountable to others and to disciplinary norms through sharing knowledge claims and artifacts with others. The activities of the scouting team also follow the disciplinary norms characteristic of the scientific enterprise as described by Ford and Forman (2006). For example, the social and material aspects of scientific enterprise and the interplay of roles, that of a constructor and critiquer of knowledge claims, is evidenced as we see the scouts working together as a community to determine the proper procedure to collect performance data on the competing robots by making claims and offering suggestions (e.g., HF-3: "We could calculate a ratio of points 
scored to points penalized, or something") on the procedures and evaluating these claims and suggestions (e.g., SA-2: "Oow? How about net points? It's easier").

Mitigating the imbalance of power through authenticity and choice

During the interviews, several students spoke of the nature of authenticity in their classroom and robotics club activities. PK compared the way that she worked with her robotics teammates and her lab partners in science class:

...in lab you have to make sure that things get done on time and that nobody gets dumped on with all the work. But what we do in robotics is more intense, we're doing it on our own because the robot is a bigger project than labs are and what you start with in lab is clearer and more certain than building a robot. In lab, you always start with a clearer idea about how to get to the goal than in robotics. Labs are always connected to what you've been learning about all year. The lab is a way to help you realize what's important about what's been going on in class. So you can, you know, get it. In robotics we have to be more creative and innovative. It comes down to getting ready for completion. There's a lot of real tension and excitement that you don't get in lab.

PK views her labs as useful but not authentic activities. She comments, "The lab is a way to help you realize what's important about what's been going on in class. So you can, you know, get it." But she says that, for her, and certainly for the teacher the outcome of the lab activity is a foregone conclusion. Everybody involved has a good idea about the outcome because "the teacher and the students have a good idea about how it will go; particularly the teacher, because he has taught the class so many times". Engagement in robotics is genuine for all involved, even for the teachers and the engineers:

It's like the teacher in science class pretends not to know; sometimes they don't even pretend they don't know how it will turn out. But in robotics none of us really know how it will turn out. The robot comes out from only our ideas. In robotics the teachers are acting as more of a guide through all of this. Really, I think that they are more important, and really more involved with us than teachers in science.

$\mathrm{HF}$, expressed opinions along these same lines:

I guess in a lab, everything is set forward, it's what you have to do is in front of you. You may figure out a few things, but the end result is, you know, is given for you. You follow the rubric and fill in the data tables and the teacher gives you a good grade. With the robotics team we're basically starting from zero from square one and going from there and ending with a robot of some kind.

$\mathrm{HF}$ argues that his science labs mainly have predetermined outcomes that only occasionally require thought and creativity. In robotics, he feels that there is less certainty of success and, as a result, more creativity and ingenuity are required. During the interviews, the students described the robotics club as an environment where they have rich and meaningful relationships with their teammates, solve real-world problems with the mentors' help, and work independently. In solving problems, they used basic scientific knowledge in conjunction with creative inquiry. Many of these same students variously described activities in their science classes as teacher-centered, trivial, contrived, vague and, like their relationships with their classmates, deficient and meaningless. These discursive resources revealed the nature students' ownership (or lack thereof) in the two 
contrasting contexts, demonstrating that the robotics club empowered the students to create and foster a collaborative community.

The issues of choice and compulsion manifested in students' and mentor's discourse of their contrasting experiences in the robotics club and the science classroom. Data analysis highlights the nature of participation in the activities, the nature of learning activities, the goals of the activities, and the relationships of students to teachers/mentors in these two contexts. As SJ shares in his interview, "I mean if we don't follow safety procedures [in the robotics club], it's more drastic than if you don't follow them in the teacher's classroom. In the classroom, you use the 1.5-volt batteries and it's just not as real." The case for the importance of the shift between the definitive "wes" of robotics to the indefinite "yous" of classroom activities is important. This shift is all the more trenchant when compared to a student's comment about performing activities "in the teacher's classroom." In science class, at least in SJ's view, he is in the teacher's classroom. This expression could be disregarded as something that arose by chance until it is put in the context of SJ's response to follow-up questions that dealt with a comparison of relationships that he has with robotics teammates and science classmates:

In robotics I'm not having to be there; I'm choosing it, to be there working on that project. If I don't want to come back, I don't have to come back. I go to school every day because I have to be there. I actually enjoy it, but most people go because they have to be there. And so the teachers that you meet at school or the teachers that you have, you're forced to get along with whether you like it or not and after school's over you have the choice to go home or go hang out with any of your other friends from school, but when, when robotics comes around, I have the choice to go home, or hang out with those other friends from school, but I choose robotics because I enjoy the people that are there, because I choose to be there.

We see from the above interview transcript that SJ acknowledges that he has a choice where robotics is concerned. This is true for the majority of the students on the robotics team. A majority of students, at some point in their interviews, made comments about the voluntary nature of robotics and the fact that science class is part of a system that requires a certain number of credits in core areas and compels them and their classmates to be in class. In terms of student/mentor relationships in the two contexts, PP responded:

...mostly you don't know science teachers as real people. You don't have time. Teachers are there to teach you. You don't work with them. You just do the stuff that they give you. You need three units of science, so you take chemistry. They have to be there and so do you. In robotics, sponsors, it's really different. We are there because we want to be; all of us, the students and the adults. You could play a sport or be in drama or go home and hang so could the sponsors.

PP's view of science class is of a situation in which the only one with agency is the teacher. The teachers act on the students by teaching them and giving them activities to do, thus subjectifying the students. The majority of the students speak of the significance and value that they find in the voluntary aspect of robotics as opposed to the compulsory nature of school classes.

\section{Talk of traction: examining power among students and mentors}

We use transcript 3 to introduce SB, the students' engineering mentor, who worked with them to build the robot. The transcript below shows the mentor SB and two team members 
(PL and PP) trying to understand and address a problem with the robot's traction. The mentor's interactions with the student members of the pit crew created a discursive space that resulted in talk that resolved the problems with the robot and the formulation of strategy for future competition. During troubleshooting and repairs, the engineering mentor did not speak often, but what he said, when he said it, and how he said it contributed to a context that insured that the students maintained a sense of community and ownership in the project. The language used during this interaction reveals how the mentor's and students' roles within the project and its goals promoted an identity of self for the students that is in more congruence with the scientific enterprise.

\section{Transcript 3}

\section{Speaker Utterances}

SB-1 All right let's, let's talk about traction.

PL-1 Yep, that's a problem because I'm not getting much of anything. So, how can we get more traction out of this thing?

PP-1 We can concentrate the mass of the batteries over the wheels.

PL-2 Don't think that'll change much. The change in lever arm is too small.

SB-2 Let's swap these like we did in the field test. That may be the ticket.

PP-2 If we take off the universals and put on the gummies that will help traction because we'll go from passive front to a four-wheel drive but it will change the handling and make us even lighter in the front. We're screwed for center of mass.

PL-3 Yeah, that won't help the hurdling or placing. The field-of-play is more like the floors at school than I thought they'd be. Yeah, maybe those tires are better. No problem with the handling. I've had time with that set-up.

PP-3 All right, but why did it fishtail? Are the wheels getting the same torque?

PL-4 Yeah. Well? When we drove it like that in the other tests it didn't fishtail, I think the new tires'll fix it.

SB-3 Uh, Guys, the way it is geared I can't see how the wheels could get different torques.

PL-5 Well, uhm, without the counterweight, I think the rear gets out of line but I can get rid of the fishtailing by accelerating less when I have to steer around a jam. The four-wheel drive'll help, too. The front won't be passive.

PP-4 Uh the, those wheels are bigger so we'll have to reposition these wires.

SB-4 Any other ideas? [2 s pause] OK, let's reroute the wiring and swap the tires.

This section focuses on Scott Bruce (SB), the mentor, and his use of language. We argue that SB used his language to advice and guide the activities of the pit crew, while simultaneously giving the students in the group space to develop their own ideas about the robot's problem, its repair, and the ramifications of the repair on the robot's post-repair capabilities. We first begin by discussing the nature of power manifested through the conversation.

Upon arriving in the pit area, SB declared that the group would focus on the robot's traction problem (SB-1: All right let's, let's talk about traction). Here SB uses effective power with the two team members to address the issue of traction. PL responds to this by acknowledging the issue (PL-1: Yep, that's a problem) and PP acknowledges the issue by offering a suggestion to fix the problem (PP-1: We can concentrate the mass of batteries over the wheels). The remaining conversation focuses on various strategies to resolve the issue of traction. The table below shows instances of effective use of power by the 
three-team members. We see that while all three members use effective power to accomplish something, SB uses it more often, and the way he uses effective power is also different. Both PL and PP use effective power in the form of asking questions to get responses from others. However, SB predominantly uses effective power in the form of declarations or soft (e.g., uses "let's") commands in the conversation. Even with SB's use of effective power to accomplish various tasks related to fixing the traction issue, we contend, as in the previous transcript, that there's relative symmetry in the power and authority among the three members of the team. For the team, SB is an individual with greater authoritative knowledge about the technical aspects of the robot than any other team member. This authority stems from his mentorship of team members, credentials, professional reputation, and demonstrated competence. Because of this, individual members of the team choose to comply with the various requests made by SB. That is, the team recognizes these requests as being reasonable requests that work toward their common goal of entering and potentially winning in the robotics competition. As a result, there is a sense of community among the members and the cost of compliance for SB and other's is low as they use effective power for the purposes of reaching the common goal (see Table 4).

It should also be noted that, in addition to the sense of community reducing the cost of compliance, SB's specific use of language also reduces the cost of compliance and possibly increases his rapport with the team members. For example, upon arriving in the pit, SB declared that the group would focus on the robot's traction problem. However, he did this with a subjunctive command: "All right. Let's talk about traction" (SB-1). This use of the subjunctive is a way of making a soft command and can be contrasted with stronger commands or declaratives, such as "We're going to talk about traction." The softer form anticipates a certain consensus about traction having been a problem for the robot in the first practice round. In their first utterances PL and PP confirm the consensus. PL and PP's acceptance of SB's declaration to talk about traction and acknowledgement of the traction issue is indicative of their agreement with SB. In his other utterances of effective power SB continues to use soft and inclusive commands to garner compliance and to ensure that all members are offered opportunities to contribute to the discussion on how the traction problem can be resolved.

Using the traction transcript, we've shown that there is symmetry in power and authority among the members of the robotics team and that this symmetry was the result of members belonging to a collaborative community. Our earlier discussions on Edelson's (1998) three attributes of science learning activities that produce symmetry in power and authority, Engle and Conant's (2002) four tenets of productive disciplinary engagement, and Ford and Forman's (2006) three disciplinary norms also apply to the conversation in the pit about traction (see Table 3 below).

Table 3 Distribution of effective use of power among participants

\begin{tabular}{lll}
\hline SB & PL & PP \\
\hline SB & PL & PP \\
SB-1: All right let's, let's talk about traction & PL-1: So, how can we get more & PP-3: All right, but \\
& traction out of this thing? & why did it fishtail? \\
SB-2: Let's swap these like we did in the field test & & \\
$\begin{array}{l}\text { SB-4: Any other ideas? [pause 2 seconds] OK, } \\
\text { let's reroute the wiring and swap the tires }\end{array}$ & & \\
\hline
\end{tabular}


Contrast in context revealing contrast in power

We interviewed the engineering and teacher mentor and asked them to share their roles in the robotic activities, classroom activities, and the industry. The teacher mentor, George Mitchell (GM) shares his experiences as a teacher and as a robotics mentor and reflected on the two contrasting contexts:

...you are more of a facilitator [in robotics] than a teacher... I think the first part of the process is getting to know the kid, and being more comfortable with those kids, it's a more relaxed atmosphere, it's not as official, if you will, as being a teacher, and you're there primarily to help these kids to use the tools that they need to use, you're there to help them think about problems, to more than anything what I try to do is just ask questions, "Will this work?" "What do you see wrong with this?"

GM continues to speak of his facilitator role as being able "to sit back and watch the kids discuss, [or to] draw .... Mentors function as sounding boards, as well, refiners of ideas, and sometimes referees for discussions. In these roles mentors facilitate discussions." GM attributes his distinctive roles in the robotics club and the classroom to the identities students assume in the two differing contexts. In contrast to his characterization of his role in the robotics competition, GM feels that in his classroom, his students view him in a more evaluative role as opposed to being a collaborative partner. This is largely due to the fact that he has the authority to determine students' "grades" and test scores. Therefore, his account of his classroom is of a space in which he and his students do not share equal power and are unable to form types of relationships that were possible in the robotics club. His use of such terms as "sponsor" and "facilitator" in the robotics club sets the stage for a dichotomy between the two contexts that is present throughout his interview. He characterizes his science classroom and the robotics team as different worlds populated by different sorts of people with different values, participating in different activities and with very different goals (Table 4).

GM's description of the two contexts parallels that of his students. In an excerpt, GM states, "this program is not in a virtual world; it's not vicarious; it's real. This is all part of a program where the kids have to figure out the answers to real world problems" and "I think that, part of the reasoning with the robotics program is to teach, doing more with less, which is kind of a realistic approach to life and business." As he compares the similarities between the robotics program and the work done by practicing scientists, the dichotomy between the real-world nature of robotics and the less authentic world of the science classroom emerges again. To emphasize these differences, GM speaks of a transformation in students' attitudes as they participate in robotics: “...traditional expectations of students is changed in the robotics environment, I think that they see it completely differently from the classroom science." He says that the students' traditional view of the classroom is one where "...the students expect all knowledge to spout from the teacher", and he contrasts this view of the classroom with one of robotics, where “...in robotics, I don't think that they look to the mentors as much, in that sense as they do as a source for simple advice in what they are trying to do."

Similar to the student participants, GM Speaks of the robotics club as a place where the sponsors and mentors take a less central role in providing information, and work with the students on teaching real world skills and observing the processes that negotiate answers to problems that the team members devise. These themes continue as GM describes the satisfaction that he gets as he sees the robotics team members learn and 
Table 4

\begin{tabular}{|c|c|c|}
\hline Author & Attributes & Interpretation \\
\hline \multirow[t]{3}{*}{$\begin{array}{l}\text { Edelson's (1998) attributes } \\
\text { for symmetry of power and } \\
\text { authority }\end{array}$} & $\begin{array}{l}\text { Examining problem has high } \\
\text { level of uncertainty }\end{array}$ & $\begin{array}{l}\text { Issue of trying to find out what was } \\
\text { wrong with the traction in the practice } \\
\text { round and how to resolve it. }\end{array}$ \\
\hline & $\begin{array}{l}\text { Meaningful consequences to } \\
\text { students' lives }\end{array}$ & $\begin{array}{l}\text { Since student and mentor participation is } \\
\text { voluntary, the students found } \\
\text { participation in robotics inherently } \\
\text { meaningful. The robotics competition } \\
\text { as an authentic and culminating } \\
\text { activity is also meaningful to the } \\
\text { students. }\end{array}$ \\
\hline & $\begin{array}{l}\text { Assessment as authentic as the } \\
\text { problem }\end{array}$ & $\begin{array}{l}\text { There is continuous self and peer } \\
\text { assessment on the progress and } \\
\text { capability of the robot. The final } \\
\text { robotics competition also serves as a } \\
\text { form of authentic assessment. }\end{array}$ \\
\hline \multirow[t]{4}{*}{$\begin{array}{l}\text { Engle and Conant's (2002) } \\
\text { tenets of productive } \\
\text { disciplinary engagement }\end{array}$} & Problematizing content & $\begin{array}{l}\text { Content (scientific enterprise and } \\
\text { physics) is problematized within the } \\
\text { context of the robotics competition }\end{array}$ \\
\hline & Giving students authority & $\begin{array}{l}\text { Participation is voluntary and there's } \\
\text { symmetry in power and authority }\end{array}$ \\
\hline & $\begin{array}{l}\text { Holding students accountable to } \\
\text { others and to disciplinary } \\
\text { norms }\end{array}$ & $\begin{array}{l}\text { Students are accountable to themselves, } \\
\text { their peers, mentors, opposing teams, } \\
\text { visitors to the competition, and to the } \\
\text { competition organizers }\end{array}$ \\
\hline & Providing relevant resources & $\begin{array}{l}\text { Students have motivation, authority, and } \\
\text { initiative to obtain relevant resources }\end{array}$ \\
\hline \multirow[t]{3}{*}{$\begin{array}{l}\text { Ford and Forman's (2006) } \\
\text { disciplinary norms of } \\
\text { authentic learning in } \\
\text { science }\end{array}$} & $\begin{array}{l}\text { Social aspect of scientific } \\
\text { practice }\end{array}$ & $\begin{array}{l}\text { Students work collaboratively and in } \\
\text { solidarity with each other and with the } \\
\text { mentors. The activity involves } \\
\text { interaction with opposing teams, } \\
\text { visitors, and judges and other } \\
\text { competition personnel }\end{array}$ \\
\hline & $\begin{array}{l}\text { Material aspect of scientific } \\
\text { practice }\end{array}$ & $\begin{array}{l}\text { The pit crew uses their developing } \\
\text { knowledge of scientific enterprise and } \\
\text { how the natural world works (scientific } \\
\text { knowledge base) as the basis for their } \\
\text { activities within the robotics } \\
\text { competition }\end{array}$ \\
\hline & $\begin{array}{l}\text { Scientific practice as an } \\
\text { interplay of roles (constructor } \\
\text { and critiquer of knowledge) }\end{array}$ & $\begin{array}{l}\text { Team members act as both constructors } \\
\text { (PP-1: We can concentrate the mass of } \\
\text { the batteries over the wheels.) and } \\
\text { critiquers (PL-2: Don't think that'll } \\
\text { change much. The change in lever arm } \\
\text { is too small.) of knowledge }\end{array}$ \\
\hline
\end{tabular}

tackle their challenges. GM contrasts the willingness and flexibility of the robotics team members with students in his classroom, whom he finds rigid, close-minded, and lacking initiative: 
For the college prep track student they, want to know how to do it; they expect you to tell them how to do it and they aren't even willing to consider the possibility that there's more than one way to approach a problem. Whereas, in robotics the kids generally show respect for other people's opinions and other ways of doing something. You will find that the robotics kids are willing to accept that. In a classroom, generally speaking, from years of teaching experience, I've actually had students get mad with me when I would show them that there is more than one way that they could do this problem. I try to get them to understand that what you need to do is look at, I don't know what word I want to use here, look at how you function and how you see things and then build your problem-solving method on what you already have and understand. Rather than take your style and adapt it to what I do. We all have a style. Part of your learning experience is to find and develop that style. And many students just absolutely hate that.

A prominent feature of GM's account is the regularity with which he speaks of the young people in his science classes as "students" and the young people on the robotics team as either "kids" or "robotics kids." We found no instances in GM's interview where there is a "kid" in one of GM's classes or a "student" on the robotics team. This is due to the fact that in the classroom context, both the teacher and the students enact different discourses. In the classroom, they are inhabitants of very different (both in context and roles played) discursive spaces. As GM and the students encounter one another in these different discursive spaces, they establish identities through their different languages, activities, values, and goals, and thus enact different discourses. However within the robotics context, GM' and the students' discursive spaces are similar and shared. This allows them to enact and participate in common discourses. It then becomes obvious, that as opposed to the robotics context, in GM's classroom there's greater asymmetry in power between GM and his students.

For GM and the students, the classroom is a place where they lack control. For both, power comes from outside of the classroom. For the students the main issues are their grades and the science credits that come with these grades. Student accounts comparing robotics to their experiences in the science classroom speak to both the students and their teachers being compelled to be in the classroom. The students' view is that they need a certain number of units of science credits and the teachers are tasked with teaching them science. For GM, issues pertaining to covering the curriculum and standardized testing are the principal means through which power is projected into the classroom. These issues also emerge in our conversations with the engineering mentor SB, who is curious about students' role in the two contexts. SB questions, "Do you see the kids expressing the same sort of ownership for activities like labs in their science classes?" He is interested in finding out about students' experiences in the science classroom, as illustrated in the following statement:

It strikes me that science class is highly repetitive. In other words the lesson plan, there's certain, there's certain first principles that have to be taught. Gravity pulls things down; heat generally makes temperature go up, right? Chemicals combine in certain ways. Whatever it is. All right and that's what you're there to teach to a large extent. So it's a knowledge base, right? So it's, it's a knowledge domain. You want the kids to be a little bit higher up in the knowledge domain. Any ability to develop solutions, to be analytical, to solve problems and that sort of thing is important, but is that really important in the curriculum to the state tests and so forth? But with 
robotics you're given basically, they unveil the objectives and you have six weeks to not only develop a solution, but to build it, test it and operate it. It feels like you're creating something from nothing.

First, SB's statement indicates that the goals of the science classroom might be at odds with a program such as robotics. It appears that he views the learning goals of the science classroom as centered on disciplinary knowledge; what SB refers to as "a knowledge domain". He contrasts this view of the science classroom with his view of learning in robotics that he sees centered on problem-solving and creative design. While SB alludes to "state tests and so forth..." GM more explicitly identifies an outside influence on the activities in the science classroom. To a question about the difference in the patterns of relationships and interactions between students and teachers, GM responded that he felt that these differences occurred:

Because of the amount of material the students are expected to learn. Especially now with No Child Left Behind, I think that most teachers feel incredible pressure to make sure that their students do well on the high-stakes testing that is a part of No Child Left Behind. The pressure to cover the topics make it hard to give students, uh, time to experiment and, and fail and uh, and I think that to some extent we should do that in science more than any other class.

Because GM is a classroom teacher, he specifically named influences such as No Child Left Behind (NCLB) and the pressures of "high stakes testing" that are part of assessments of Adequate Yearly Progress (AYP) that make the power relations between students and teachers in the classroom very distinct from an after school activity such as the robotics club. GM's role and experiences as a classroom teacher and being a robotics mentor for several years allow us to have insights into how he views his identity and his role in the mediation of power in the two contexts. His interview captures experiences of moving between two worlds: the robotics club and his science classroom.

\section{Re-constructing power and enactment of authentic science experiences}

Our study of the students and the mentors as they participated in the robotic competition examined the context of their participation and the use of language to understand how power is manifested and then mediated. Through our analysis of competition transcripts and interviews we noticed that both students and mentors participated in authentic science experiences and productive disciplinary engagement in the robotics activity. This was possible because of the voluntary nature of the participation and the creation of a collaborative community. Students and mentors had common goals and interests for which they shared responsibilities and understood each other's limitations and expertise. This enabled them to work together to realize the goals of the robotics competition. The participants' collaborative work revealed the manifestation and mediation of power through the use of language. However we note that because of the sense of community among the participants, there was also symmetry in power and authority among participants. All of this enabled the participants to engage in a type of scientific enterprise, part of which includes co-constructing and critiquing each other's knowledge claims.

As students' scientific practice become similar to those in the scientific community, they experience greater authenticity not only in the practice itself, but also in the learning of science. As it relates to the conditions under which authentic science learning is likely to 
occur, this study does two things. It adds new dimension to what has already been established about the conditions under which authentic science learning is likely to occur (e.g. Jimenez-Aleixandre, Rodriguez and Duschl 2000) by revealing the mediation of power and the presence of symmetry in power in authentic learning contexts. Additionally, this study connects those conditions to a novel learning context, the robotics competition. It presents an argument that in the robotics club, the language and context reflexively influence one another and reduce the imbalance of power between the students and the mentors. This shift in power created a space for authentic and meaningful science learning, where student discourse was descriptive, relational, explanatory, and had an authentic evaluative dimension (Gomez 2007).

An aspect of authentic science learning is for students to display solutions and to explain and account for their results (National Research Council 2000). The aspect of public performance found within the robotics competition, long hours of work, sizable expenditure of resources, the voluntary nature, and the ownership for the work among group members created a collaborative space for the members to participate in scientific enterprise through co-constructing and critiquing each other. This public performance aspect of the robotics club places the team members and its mentors before a community of peers outside of their immediate and regular association. Rod Watson, Julian Swain, and Cam McRobbie (2004) suggest that students resist or simply do not see the need of discussing or explaining themselves before an audience of classmates and a teacher who already know full well what their activity has been or what result their work has achieved. We add that when students experience authentic activities during which they create new knowledge claims, artifacts, and models and assert ownership toward these, there is greater likelihood that the students will participate in explaining, defending, and presenting these for external critiques. In the Watson et al.'s study, students did not explain their activity and results to investigators, who had been in the classroom during the activity. However, they eagerly explained, at length, both of these things to visitors who had not been present during the activity. Warren Bernard (2003) reports similar findings in his study of students involved in science projects.

Within the context of the robotics competition, students felt empowered as their ideas determined how the activity unfolded. When the role of the mentor changed to become a facilitator, knowledgeable co-investigator, and co-critiquer, there was a shift in power that allowed students to take an active hand in planning and conducting authentic learning experiences. In contrast, the language used by the students as they spoke of the science classroom did not speak of relationships, activities, experiences, or accomplishments that gave them experiences of participating in authentic science learning activities. Instead, they spoke of lack of collaborative community with classmates and their teachers and of relationships that were imposed on them by factors beyond their control. They spoke of classroom activities that seemed to have vague goals, did not have much purpose beyond the performance of a procedure that were less meaningful, and were not engaging. For example, they described that their lab exercises were designed to confirm some relationship among variables or a connection between a cause and an effect that has already been established by others. However the outcomes for the robotics project were never assured, and hinged on the creativity, initiative, and to some extent, the persistence of the group.

The findings from this study suggest three possible ways in which the science classroom can be transformed into an authentic learning context. First, the students should have the opportunity to examine questions that represent true uncertainty in their world. Second, these questions must have consequences that hold important meaning for the students. 
Lastly, classroom contexts should include authentic final assessment/s that might also include peer assessment.

Students' language indicated that they felt little ownership or connection with the activities in their science classrooms. The use of language gave no indication of student agency in selecting the activities, structuring the activities, or having control over their outcomes. Students spoke of being compelled to attend school, and being compelled by graduation and post secondary institutional requirements to take certain classes. Their concerns centered on getting the work done and earning a good grade, which suggests that the students really did not identify with the activities and products of their classroom. These student accounts of the science classroom showed that for them all loci of valuation lie outside of their control, and that for them education had become nothing more than "mere procedural consumerist expectations" (Boyles 2007). Students' views were similar to their teacher mentor's view of activities in the science classroom. Mentors' use of language showed that they, too, saw little immediate value in many science classroom activities. Instead, one of the mentors saw the valuation of his and his students' efforts resting with the assessors of benchmark test results, high school graduation and/or test scores. These externally imposed factors (the mandates of overly broad curricula, endless preparation for high stakes tests, and the rafts of paperwork connected to teacher accountability) make it difficult to replicate the elements of the robotics competition in the science classroom that are important to promoting authentic scientific experiences. The participants' accounts of the classroom are very similar to accounts of public education in the United States documented by various authors (e.g. Baez and Boyles 2009) who argue that public education is currently defined by the reductionism. The purpose of the classroom continues to be for doing school (Jimenez-Aleixandre et al. 2000) and not for engaging in authentic disciplinary practices; therefore the classroom has become a place for doing accountability (Baez and Boyles 2009). May be, what goes on in the classroom is the problem. Jay Lemke (2007) suggests that the traditional classroom setting may be so flawed that it and traditional schools should be abandoned in favor of alternative sites and modes of education.

\section{Possibilities for informal and school science intersection?}

Student participation in out-of-school experiences such as science clubs are less constrained by school bells and lesson times and has the potential to provide authentic science learning experiences. Out-of-school science learning becomes more authentic than much of what goes on in science classrooms when it helps demonstrate or replicate the sort of work that scientists frequently undertake, or when it is perceived as having relevance to solving real-life problems (Rennie, Feher, Dierking and Falk 2003). Well-designed out-of-school learning experiences allow students to draw on more sites of data gathering and knowledge production and allows for a contemporary, collaborative, and transdisciplinary science. In addition this allows science learners and facilitators (teachers) to have symmetry in power as they co-construct and critique scientific knowledge claims.

The current study provides some insights into how context facilitated students' and their mentor's use of appropriate language to mitigate power imbalances that resulted in authentic disciplinary engagement. After many years of attempts to institute science pedagogy based on student-centered approaches, high school science classrooms in the United States are still dominated by teacher-centered activities, and even those activities that do involve students in hands-on activities fall short of authentic disciplinary practices. 
Having noted this, the literature does include some examples of successful authentic science learning. Frequently, these successes occur outside of the classroom in extracurricular projects through extended activities (Almeida, Bombaugh and Mal 2006). Falk and Dierking (2010) also challenge the assumption that the school is the primary place where students learn science, saying that 95 percent of science learning occurs outside of the science classroom. Thus, it is important for us to acknowledge both the limitations of science learning in school settings and the potential of science learning opportunities in informal settings for authentic disciplinary engagement and public understanding of science. Additionally as we identify characteristics that empower individuals to engage with science in informal settings, we may be able to design hybrid spaces that intersect informal learning and school science to create authentic, meaningful, and accountable learning experiences for students. While, we don't claim to have answers to these complex conversations, we recommend that the type of student talk and community building enacted in the robotics competition need to find a way into science classrooms if the goal is for the students to authentically represent the disciplinary practices of science. When students do this, it will also lead to them having ownership and agency for their educational experiences.

\section{References}

Adams, J., Luitel, B. C., Afonso, E., \& Taylor, P. C. (2008). A cogenerative inquiry using postcolonial theory to envisage culturally inclusive science education. Cultural Studies of Science Education, 3, 999-1019.

Almeida, S., Bombaugh, R., \& Mal, T. K. (2006). Involving school children in the establishment of a longterm plant biodiversity study of an urban greenspace. American Biology Teacher, 68, 213-220.

Baez, B., \& Boyles, D. R. (2009). The politics of inquiry: Educational research and the "culture of science". Albany: State University of New York Press.

Bakhtin, M. M. (1981). The dialogic imagination. Austin: The University of Texas Press.

Bernard, W. (2003). Authentic research projects: Students' perspectives of the process, ownership, and benefits of doing research. Ph.D., Unpublished Doctoral Dissertation. Georgia State University, Atlanta.

Bogden, R. C., \& Biklen, S. K. (2003). Qualitative research for education: An introduction to theories and methods (4th ed.). Boston: Allyn and Bacon.

Boyles, D. R. (2007). Comments on no child left behind. Educator Roundtable: http://www.youtube.com/ watch? $\mathrm{v}=\mathrm{NCsu} 9 \mathrm{xwAZJo}$

Brown, P., \& Levinson, S. (1978). Universals in language usage: Politeness phenomena. In E. Goody (Ed.), Questions and politeness: Strategies in social interaction (pp. 56-324). Cambridge: Cambridge University Press.

Candela, A. (1999). Students' power in classroom discourse. Linguistics and Education, 10, 139-163.

Dawes, L. (2004). Talk and learning in classroom science. International Journal of Science Education, 26, $677-695$.

Dewey, J. (1920). Reconstruction in philosophy. New York: Henry Holt and Company.

Dierking, L. D., Falk, J. H., Rennie, L. J., Anderson, D., \& Ellenbogen, K. (2003). Policy statement of the "Informal Science Education" ad hoc committee. Journal for Research in Science Teaching, 40, $108-111$.

Duranti, A., \& Goodwin, C. (1992). Rethinking context: Language as an interactive phenomenon. In A. Duranti \& C. Goodwin (Eds.), Studies in the social and cultural foundations of language (pp. 1-42). Oxford: Cambridge University Press.

Duschl, R. A., \& Osborne, J. (2002). Supporting and promoting argumentation discourse in science education. Studies in Science Education, 38, 39-72.

Edelson, D. C. (1998). Realizing authentic science learning through the adaptation of science practice. In B. J. Fraser \& K. Tobin (Eds.), International handbook of science education (pp. 317-331). Dordrecht: Kluwer. 
Engle, R. A., \& Conant, F. R. (2002). Guiding principles for fostering productive disciplinary engagement: Explaining an emergent argument in a community of learners classroom. Cognition and Construction, 20, 399-483.

Ervin-Tipps, S., O’Connor, M. C., \& Rosenberg, J. (1984). Language and power in the family. In C. Kramarae \& M. Schutlz (Eds.), Language and power (pp. 116-135). Urbana: University of Illinois.

Fairclough, N., \& Wodak, R. (1997). Discourse as social interaction. In T. A. van Dijk (Ed.), Discourse studies: A multidisciplinary introduction (Vol. 2, pp. 258-284). London: Sage.

Falk, J. H. (2001). Free-choice science education: How we learn science outside of school. New York, NY: Teachers College Press.

Falk, J. H., \& Dierking, L. D. (2010). The 95 percent solution: School is not where most Americans learn most of their science. American Scientist, 98, 489-493.

Ford, M. J., \& Forman, E. A. (2006). Redefining disciplinary learning in classroom contexts. Review of Research in Education, 30, 1-32.

Ford, M. J., \& Wargo, B. M. (2007). Routines, roles and responsibilities for aligning scientific and classroom practices. Science Education, 91, 133-157.

Foucault, M. (1972). The archaeology of knowledge. London: Routledge.

Foucault, M. (1979). Discipline and punish: The birth of the prison. New York: Vintage.

Gee, J. P. (2005a). An introduction to discourse analysis theory and method (2nd ed.). New York: Routledge.

Gee, J. P. (2005b). Language in science classroom: Academic social languages as the heart of school-based literacy. New Jersey: Lawrence Erlbaum.

Geertz, C. (1973). The interpretation of culture. New York: Basic Books.

Gomez, K. (2007). Negotiating discourses: Sixth-grade students' use of multiple science discourses during a science fair presentation. Linguistics and Education, 18, 41-64.

Hsu, P.-L., Roth, W.-M., Marshall, A., \& Guenette, F. (2009). To be or not to be? Discursive resources for (dis-) identifying with science-related careers. Journal of Research in Science Teaching, 46, 1114-1136.

Jimenez-Aleixandre, M. P., Rodriguez, A. B., \& Duschl, R. A. (2000). "Doing the lesson" or "Doing science": Argument in high school genetics. Science Education, 84, 757-792.

Kelly, G., Brown, C., \& Crawford, T. (2000). Experiments, contingencies, and curriculum: Providing opportunities for learning through improvisation in science teaching. Science Education, 84, 624-657.

Lemke, J. L. (2007). Re-engineering education in America. Language Arts, 1, 52-60.

National Research Council. (2000). Inquiry and the National Science Education Standards: A guide for teaching and learning. Washington, DC: National Academy Press.

Ng, S. H., \& Bradac, J. J. (1993). Power in language: Verbal communication and social influence. Newbury Park, CA: Sage Publications.

Rennie, L. J., Feher, E., Dierking, L. D., \& Falk, J. H. (2003). Toward an agenda for advancing research on science learning in out of school settings. Journal of Research in Science Teaching, 40, 112-120.

Ritchie, S. M., \& Rigano, D. L. (2002). Discourses about a teacher's self-Initiated change in praxis: Storylines of care and support. International Journal of Science Education, 24, 1079-1094.

Rosebery, A. S., Warren, B., \& Conant, F. R. (1992). Appropriating scientific discourse: Findings from language minority classrooms. The Journal of the Learning Sciences, 2, 61-94.

Roth, W.-M. (1993). Metaphors and conversational analysis as tools in reflection on teaching practice: Two perspectives on teacher-student interactions in open-inquiry science. Science Education, 77, 351-373.

Roth, W.-M. (2007). Toward solidarity as the ground for changing science education. Cultural Studies of Science Education, 2, 721-783.

Roth, W.-M., \& Bowen, G. M. (1995). Knowing and interacting: A study of culture, practices, and resources in a grade 8 open-inquiry science classroom guided by a cognitive apprenticeship metaphor. Cognition and Instruction, 13, 73-128.

Roychoudhury, A., \& Roth, W.-M. (1996). Interactions in an open-inquiry physics laboratory. International Journal of Science Education, 18, 423-445.

Vygotsky, L. (1981). Learning through interaction: The study of language development. Cambridge: Cambridge University Press.

Watson, J. R., Swain, J. R. L., \& McRobbie, C. J. (2004). Students' discussions in practical scientific inquiries. International Journal of Science Education, 26, 25-45.

Wood, L. A., \& Kroger, R. O. (2000). Doing discourse analysis: Methods for studying action in talk and text. Thousand Oaks, CA: Sage Publications. 


\section{Author Biographies}

Anton Puvirajah a former high school science teacher, is an assistant professor of science education at Georgia State University. He completed his undergraduate studies at the University of Manitoba and received his Ph.D. in Curriculum and Instruction from Wayne State University. His research interests include examining students' scientific reasoning and the nature of the learning environment that facilitates students' meaningful science talk and reasoning. Within this paradigm he is currently studying how teachers and students examine and make sense of their personal epistemological stances related to science ideas. In addition to conducting research, he teaches both undergraduate and graduate courses in Science Teacher Education, works closely with his graduate students in designing project-based science curricula for AfterSchools All-Stars-Atlanta, and conducts professional development workshops for area science teachers.

Geeta Verma is an associate professor of science education at University of Colorado Denver. Prior to this, she was an Assistant/Associate Professor at Georgia State University. She holds a Ph.D. from Kent State University, a MS and BS in Zoology from University of Delhi as well as a M.Ed. from University of Delhi. Her research work, grounded in sociocultural theory, integrates equity issues in science education, curriculum discourse, and ethnic studies in immigrant communities. In particular, she is interested in finding out how pre-service and in-service teachers explore curricular, pedagogical, and instructional spaces in their classrooms to facilitate access to science. Her work has been published in various peer-reviewed journals such as Journal of Science Teacher Education; the Journal of College Science Teaching; the Journal of Curriculum, and Pedagogy; Science Scope; and Science and Children. She recently published a book titled; "Science and Society in the Classroom: Using Sociocultural Perspectives to Develop Science Education" and served as panel reviewer for the National Selection Committee (NSC) for the Presidential Awards for Excellence in Mathematics and Science Teaching (PAEMST) administered by National Science Foundation. Dr. Verma serves as the associate editor for the Electronic Journal of Science Education and on the editorial and review board of many journals.

Horace Webb has taught science in the Cherokee County School System in Canton, Georgia for twentyfour years. Webb's studies in biology and subsequent degrees from Emory University were an extension of a childhood fascination with birds. He also attended Georgia State University where he earned a M.Ed. and $\mathrm{Ph}$. D. degree in science education. Webb and his wife served in Peace Corps in the Solomon Islands. During this time, he further developed his interest in ornithology and got interested in the use of language in teaching. These interests and his service in the Solomon Islands have shaped his activities since his return from Peace Corps. Upon his return, he began teaching science, and with the help and encouragement of Dr. Jared M. Diamond made return trips to the Solomon Islands under the auspices of a Frank M. Chapman Grant from the American Museum of Natural History. These trips resulted in the publication of several articles in peer-reviewed ornithological journals with Webb as sole or co-author. His interest in language informs his professional practice as a science teacher and he is interested in studying factors that shape discourse in science learning. 